\title{
ENTRE O VISÍVEL E O NÃO VISÍVEL: OS POTENCIAIS ETNOGRÁFICOS DOS RETRATOS DE família numa comunidade RURAL de Minas Gerais
}

Paulo Augusto Franco de Alcântara ${ }^{1}$

UFRJ, Rio de Janeiro, Brasil

\begin{abstract}
Partindo de imagens coletadas ao longo de dois anos de pesquisa etnográfica em Santo António do Rio das Mortes Pequeno, distrito rural de São João del Rei, o texto abordará os retratos de familia no seu potencial antropológico. Acredita-se que a fotografia, na sua qualidade de fuir entre o visivel e o não visível, na composição de indícios de significação sociocultural de uma época, se constitui como olhares sobre as realidades sociais. Se olhares são escolbas e, portanto, o resultado de processos sociais, as fotografias possuiriam lugares sociais de produção, obedecendo a padrôes formais, estéticos e morais de uma época. Considerando os diversos aspectos e papéis das fotografias e dos fotógrafos em espaços rurais, serão propostas reflexões sobre os usos da fotografia na prática etnográfica, apontando para o seu potencial na sugestão/revelação do "olhar" que a produziu. Em seguida, serão propostas breves leituras de imagens coletadas nos arquivos familiares, destacando, como base para a reflexão, as noções de performatividade e de representação no sentido da montagem/construção imagética diante da pretensão de memória. Palavras-chave: fotografia, etnografia, família, memória, espaço rural
\end{abstract}

\section{INTRODUÇÃo: GUARDAR, CONGELAR E ETERNIZAR PARA, ENFIM, CIRCULAR}

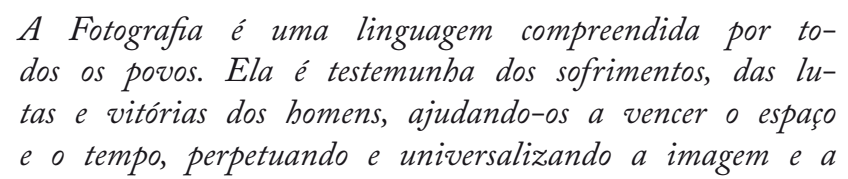
dos os povos. Ela é testemunha dos sofrimentos, das lutas e vitórias dos homens, ajudando-os a vencer o espaço e o tempo, perpetuando e universalizando a imagem $e$ a

1 Doutorando em Antropologia Cultural PPGSA/IFCS. Membro colaborador do Núcleo de Antropologia Visual e da Arte NAVA/CRIA, Lisboa. Trabalho apresentado nas Conferências NAVA, Antropologia Visual em Rede: Usos da imagem. Pesquisa, Rodagem, Montagem. Lisboa, 24 de Maio de 2014. Contato do autor: guto.franco@ gmail.com. 
bistória dos individuos e da Humanidade. As civilizações que não conheceram a Fotografia morreram duas vezes. José Inácio Parente, in «Rio de Memórias», 1987

Falar sobre a fotografia ou, mais precisamente, sobre o retrato como experiência de memória remete, num primeiro plano de reflexão, para o congelamento em imagem de ocasiões especiais ou atos e fatos extraordinários contidos no cotidiano. Através da sabedoria popular, compreendemos a fotografia através dos intransitivos congelar, eternizar, guardar, gravar. Por essas compreensões correntes do ato de registo, podemos pensar a fotografia como empreendimento que, como as artes plásticas, pretende elementarmente parar o tempo na sua forma quantitativa no intuito de promover, para o futuro, a contiguidade de relações e de sentimentos. Nesse sentido, a história da fotografia coincidiria com a história da representação.

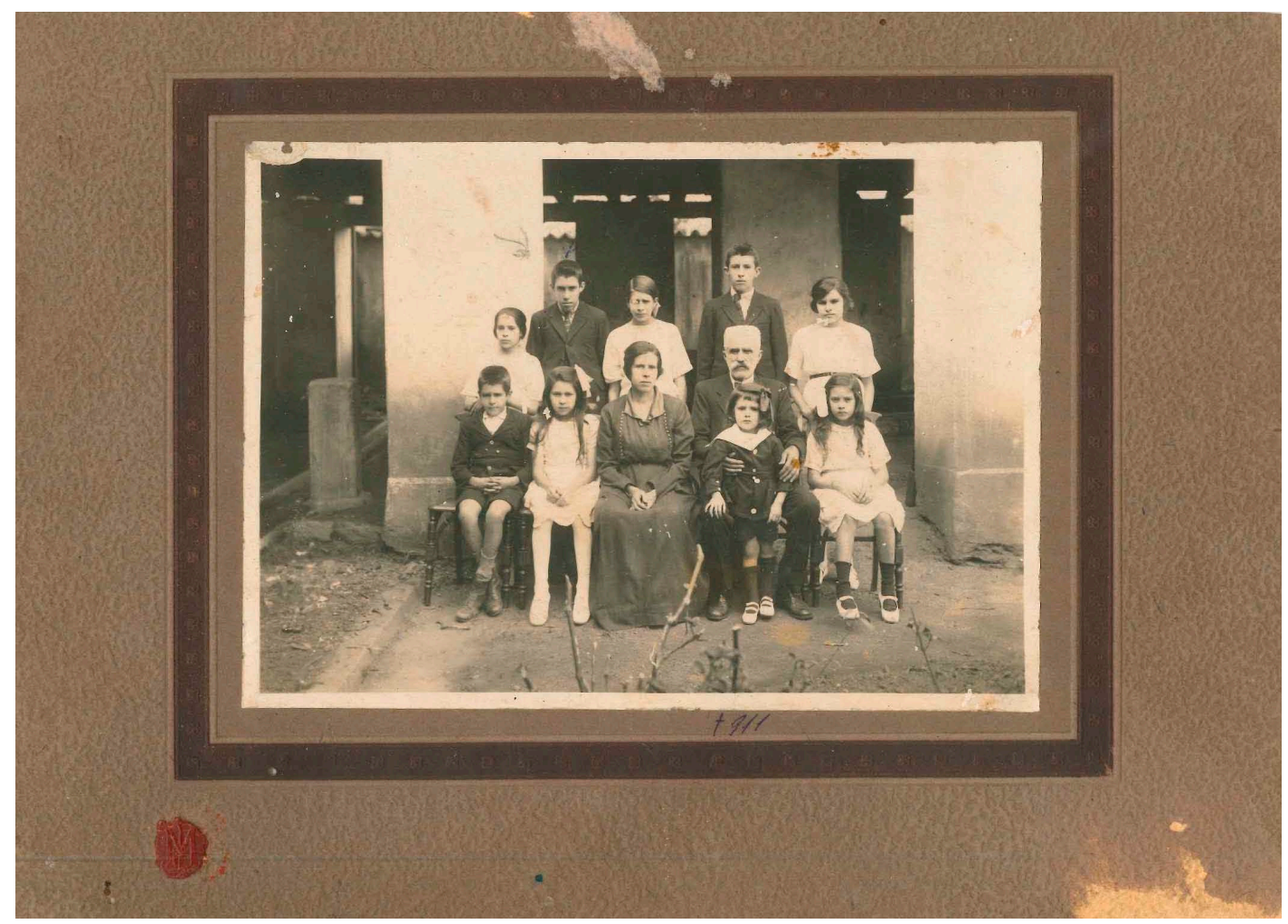

Foto 1. Seu Carneiro, Dona Olívia e filhos. A família retratada é constantemente atualizada pela memória dos moradores locais como uma das mais importantes e influentes na política e na religiosidade do Rio das Mortes. O filho localizado na fileira dos fundos, à extrema esquerda, é "Zeca do Carneiro", reconhecido como o mais autoritário Juiz de Paz que a comunidade já teve. Meados dos $\operatorname{anos} 30$.

Esforçando-se por eliminar os riscos do efêmero e do acidental, a fotografia converte a experiência do real em cena, exagerando relações, gestos e posturas. Como qualquer modalidade do mesmo gênero representacional, a fotografia pode transmitir padrões, regras e situações de formalidade operando, segundo Pierre Bourdieu, um "corte instantâneo no mundo visível" (2006: 39), que por sua vez tornará consignado em si o tempo de uma família, de um grupo, de festas e de espaços ${ }^{2}$.

2 Através de uma leitura de Durkheim (1995), poderíamos situar a fotografia no âmbito do seu potencial de constante atualização de sentidos e sentimentos através de sua cerimonialidade própria, promovendo, por reafirmação, a unidade ou a coesão de um grupo. Tal interpretação teria a memória como eixo de compreensão da qualidade da imagem, bem como de sua apropriação como evento ou marco da vida civil ou familiar de um povo. 
A fotografia, nesse sentido, assume as feições e potenciais da recordação e do legado, movimentos pelos quais os indivíduos buscam reanimar narrativamente as suas presenças no mundo através de relações e papéis exercidos socialmente e cerimonialmente. Mais do que isso, a imagem oferece a oportunidade do indivíduo interferir e criar no próprio mundo, rearranjando-o, ressignificando-o para futuros e invisíveis olhares (falarei mais detalhadamente sobre esse potencial na sequência do texto).

Como na rica citação que introduz e inspira este texto, as fotografias servem como "testemunhas dos sofrimentos, das lutas e vitórias dos homens, ajudando-os a vencer o tempo e o espaço" e, para além dessa constatação, a fotografia, segundo Peter Burke (200: 183), surgiria como "testemunha ocular" de um tempo que se revela informando relações, padrões e estéticas sociais.

Na perspectiva semiológica de Roland Barthes (1977), podemos coincidir o ato da fotografia como "imitação" ou "cópia" da realidade concebida e vivida, considerando as mensagens contidas na imagem no seu fator de transmissão artístico-textual ou de reconstituição do passado.

Sendo assim, como mecanismo de apreensão do tempo e do espaço histórico, como potencial aflitivo para vencer o efêmero, como ferramenta de memória e de coesão ou como simplesmente recurso mimético e de colagens, a fotografia, no denominador comum dessas ideias, constitui-se como mecanismo de registro social e artístico, como momentos de significações capazes de informar - e Gilberto Freyre (1983: 18) as qualifica como "informes pictórios" - a respeito de visões de mundo e configurações das relações sociais de uma época.

"Realidade exagerada", "imitação" ou potencial de "performances", a fotografia poderia ser enfrentada com uma possível reflexão de realidades as quais são construídas socialmente através de faculdades cognitivas e/ou inconscientes. Nesse sentido, estando a fotografia dependente do entendimento de quem a contempla, seria, nas palavras de Lévi-Strauss, "boa para pensar" a realidade (1965: p. 128) ou, por analogia à magia maussiana poderíamos percebê-la menos como “arte técnica”, mas como um verdadeiro "tesouro de ideias" (Mauss, 2003: 175).

Em Minas Gerais, a primeira fotografia, um daguerreótipo ${ }^{3}$, foi feita no ano de 1845 pelo retratista francês Hypolito Lavenue. Desde então, o ofício incorporado por outros, foi sendo difundido pelo interior, configurando hábitos e expectativas tanto dos chamados retratistas itinerantes quanto de famílias que esperavam ansiosas pelo "dia do retrato". Esses retratistas 'itinerantes', 'ambulantes' ou 'volantes' circulavam por longos trechos, de vila em vila, em trens ou no lombo de animais, com o intuito de garimpar serviços, sem geralmente possuir clientelas fixas (Arruda 2013: 19). Essa "cultura da andança" que, na história social brasileira deve ser identificada para além de estritos aspectos econômicos, se apresenta como característica da própria mentalidade do indivíduo. Constituindo-se como uma mobilidade inevitável (Franco 1997: 32), a itinerância foi a principal qualidade responsável por difundir no interior brasileiro a prática e

3 Inventado por Louis Jacques Mandé Daguerre (1787-1851), o daguerreótipo constituía numa placa de cobre amalgamada e uma fina lâmina de prata cuja superfície polida lembrava um espelho. Essa superfície se tornava fotossensível por meio do iodeto de prata. Ao contrário do sistema negativo-positivo que a sucederia na história, a imagem obtida já se tornava o produto final, sem a possibilidade de reprodução. Recurso bastante apreciado socialmente, o daguerreótipo foi sendo apresentado sob diversos formatos estéticos, montado em estojos ornados com veludo e passe-partouts dourados. Esses recursos, segundo Kossoy, foram ao encontro dos "padrões burgueses de gosto da época" (2002, p. 23). 
o gosto pela fotografia, contribuindo para a construção da imagem do homem brasileiro.

Normalmente regida pala ambivalência existente entre o fascínio tipicamente causado e a desconfiança local, o ofício da fotografia pelas mãos de um forasteiro foi sendo incorporada por diversas comunidades do interior de Minas Gerais como evento capaz de mobilizar famílias e suspender o cotidiano local. Mas, foi por serem muitas vezes identificados como "agentes da modernidade" é que esses fotógrafos em constante circulação passaram a compor o cotidiano de cidades e de comunidades do interior.

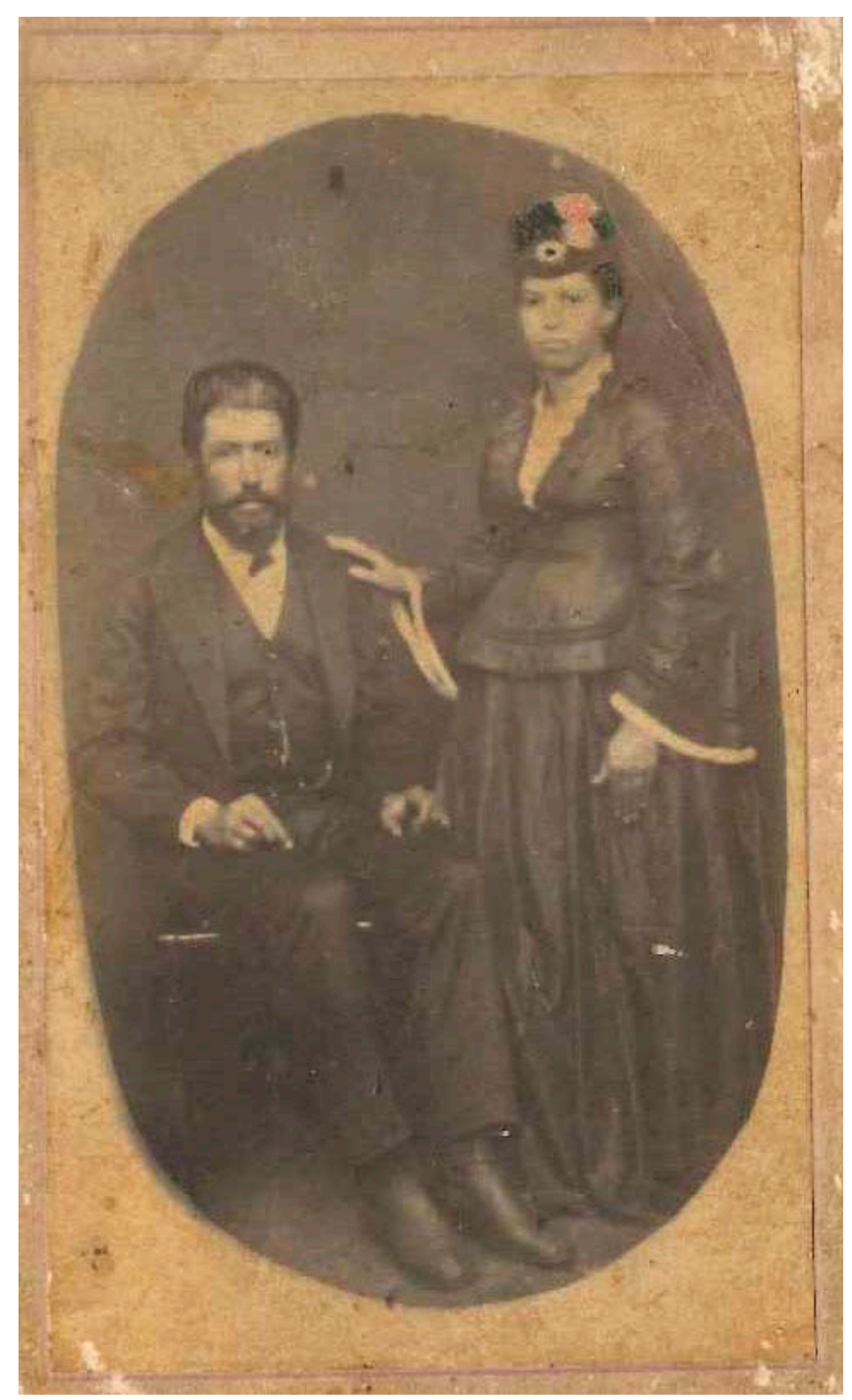

Foto 2. Casal desconhecido. A expressão de tempos patriarcais no Rio das Mortes. Data desconhecida.

Mas não apenas os fotógrafos circularam. Os retratos também possuíram um intenso traço de mobilidade. A chamada carte de visite, criada em 1854, em França por Adolphe Engène Disderi, foi incorporada pelos retratistas brasileiros e mineiros da época, impulsionando uma maior popularização dos retratos. Nesse gênero fotográfico, que se destinava a produzir retratos 
de casais, crianças e famílias para enviar a parentes e amigos mais distantes, passou a padronizar poses e semblantes, enquanto a imagem recebia um tratamento superficial com usos constantes de mesmos fundos/cenários compostos por mesinhas, cortinas, vasos de flores, colunas ${ }^{4}$. Esses novos "movimentos" foram responsáveis por trazer à fotografia uma maior "penetração popular" (Vasquez 1983: 30).

Percebemos, então, que a fotografia surge em movimentos humanos, como objeto de trocas reguladas, marcando práticas cerimoniais e atualizando costumes e rituais. Como cartões, as fotografias assumem a mediação de "reconhecimentos mútuos" (Bourdieu \& Bourdieu 2006: 33), como recordação, reafirmam presenças e ausências e, como arquivos, remontam parentescos e identificam gerações no sentido de mapeamentos genealógicos. Nesse sentido, a fotografia pode informar a imagem de indivíduos e de grupos familiares nas suas fisionomias, posturas, gestos, interações, enfim, diante de seus ritos de passagem e eventos mais representativos da vida em sociedade.

Partindo desses breves e gerais apontamentos, este ensaio terá como principal enfoque o tratamento da fotografia como potencial memorialístico, tanto no seu sentido de materialização de conteúdos sociais relevantes através de representações e de cerimonialidades, quanto no seu caráter de propiciar ao pesquisador variadas leituras e temporalidades a respeito do concebido, do percebido e do vivido. Parto, nesse sentido, do pressuposto oferecido por José de Souza Martins, de que a fotografia, ao mesmo tempo em que "congela" um determinado instante, o "descongela" sociologicamente nas variadas possibilidades de interpretação de uma imagem (histórica) (2002: 224). Somo a isso a ambivalência concedida por Lilia Moritz Schwarcz à imagem a qual, ao mesmo tempo em que "plasma uma realidade", cria valores e representações. Nesse sentido, "as representações não são somente um produto, elas produzem também realidades.” (2010: 92).

No intuito de desdobrar e relacionar essas questões apresentadas com as potencialidades dos usos da fotografia na pesquisa em antropologia, apresentarei e analisarei fotografias reproduzidas a partir de alguns arquivos familiares aos quais tive acesso durante uma etnografia realizada no distrito rural de Santo Antônio do Rio das Mortes Pequeno entre os anos de 2011 e $2013^{5}$.

Como o objeto de minhas pesquisas na época tinha centralidade na memória acerca dos papéis exercidos por juízes de paz na região, entrevistei durante aqueles anos parentes e pessoas que se relacionaram com esses juízes cujas principais atribuições eram a realização de casamentos civis e a conciliação de conflitos relativos à família e à propriedade privada (terras). Na busca por relatos e documentos pessoais, conheci e conversei com indivíduos de variados perfis socioeconômicos, destacando desde aqueles pequenos proprietários de terras e sitiantes, até membros de famílias conhecidas localmente como a "elite" no passado.

Como os principais e mais vastos arquivos fotográficos familiares surgiram do primeiro grupo de interlocutores no campo, concederei centralidade a esses documentos. Ao tratarem

4 Nas cidades, como no Rio de Janeiro e em São Paulo, esse gênero foi acompanhado pelo surgimento dos "salões de pose", verdadeiros estúdios localizados em sobrados urbanos que atraiam especialmente a burguesia local em busca do "modelo (europeu) de representação" propiciado pela carte de visite (Kossoy 2002: 36-40)

5 A pesquisa foi realizada no contexto de produção de minha dissertação de mestrado defendida em agosto de 2013, na Universidade Federal Fluminense. 
de pessoas com certa inserção social privilegiada, assumo que tais fotografias possuem inevitavelmente lugares de produção formal e simbólica próprias a uma classe dominante com um mais amplo acesso, na época, ao mercado da fotografia. Esse grupo envolvia, especialmente, as famílias dos fazendeiros.

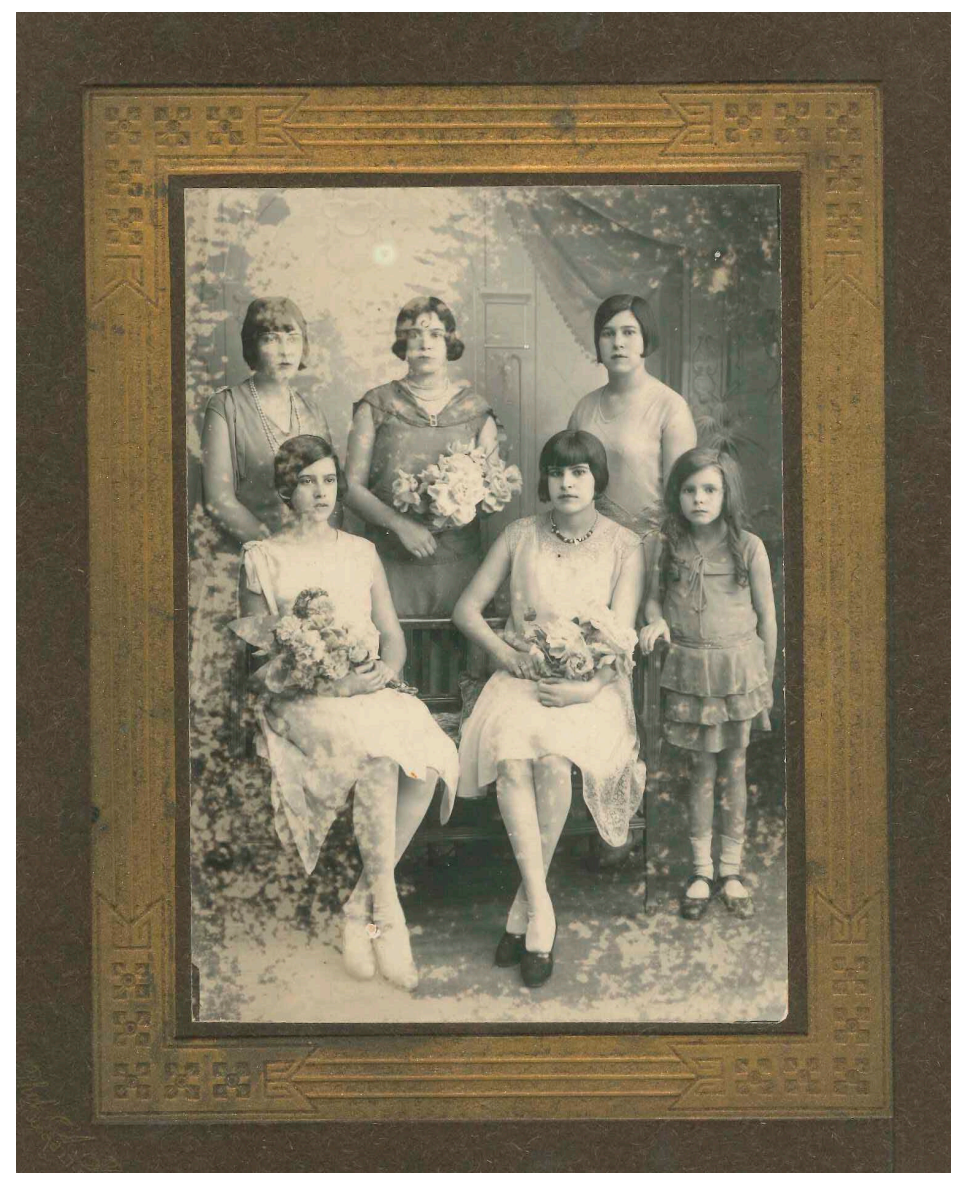

Foto 3. Irmãs do Zeca do Carneiro e a performance feminina na fotografia. Meados da década de 40.

No que se refere ao manuseio de imagens na etnografia, terei a oportunidade de, neste trabalho, usar essas imagens, para além de ilustrações de contextos memorialísticos apresentados oralmente por meus informantes, como testemunhas de processos sociais, relações, moralidades, modelos estéticos e representações locais. Considero que, no contexto deste trabalho, as fotografias não surgem apenas como indícios ou como recomposição do passado, mas, sobretudo, como "vestígios documentais de múltiplas existências" (Kossoy 2002: 25), ou seja, como verdadeiro corpus documental a respeito de imaginários sobre esse passado: sobre realidades as quais, no presente, reformulam constantemente as noções de história e de memória. A imagem ressurge, então, como artefato etnográfico.

\section{Presenças e ausências: A fotografia na prática etnográfica}

As possíveis relações entre a Antropologia e a fotografia já não são novidades. Dessa forma, concebe-se, de maneira corrente, a fotografia tanto na sua materialidade histórica, quanto 
no seu potencial de produção de sentidos ao passo que documenta o "olhar" que a produziu (Novaes 1998: 116), considerando a sua inserção num contexto de práticas, costumes e crenças, enfim, no "mundo social" (Martins 2002: 223).

Desde as minhas primeiras experiências com a pesquisa de campo em comunidades rurais do interior de Minas Gerais, o exercício de memória empreendido no sentido de perceber visões e percepções sobre justiça, ordem e autoridade no passado foi constantemente auxiliado e intensificado pela exibição e contemplação de imagens fotográficas. Em algumas das situações, usadas como fórmulas de se provar ou vigorar um fato narrado, em outras como recurso para se lembrar melhor, as fotografias tiveram interessantes e variadas funções em construções narrativas de meus informantes, tornando-se, em muitas ocasiões, verdadeiros pretextos para novos casos e chegando até a interferir no rumo das pesquisas.

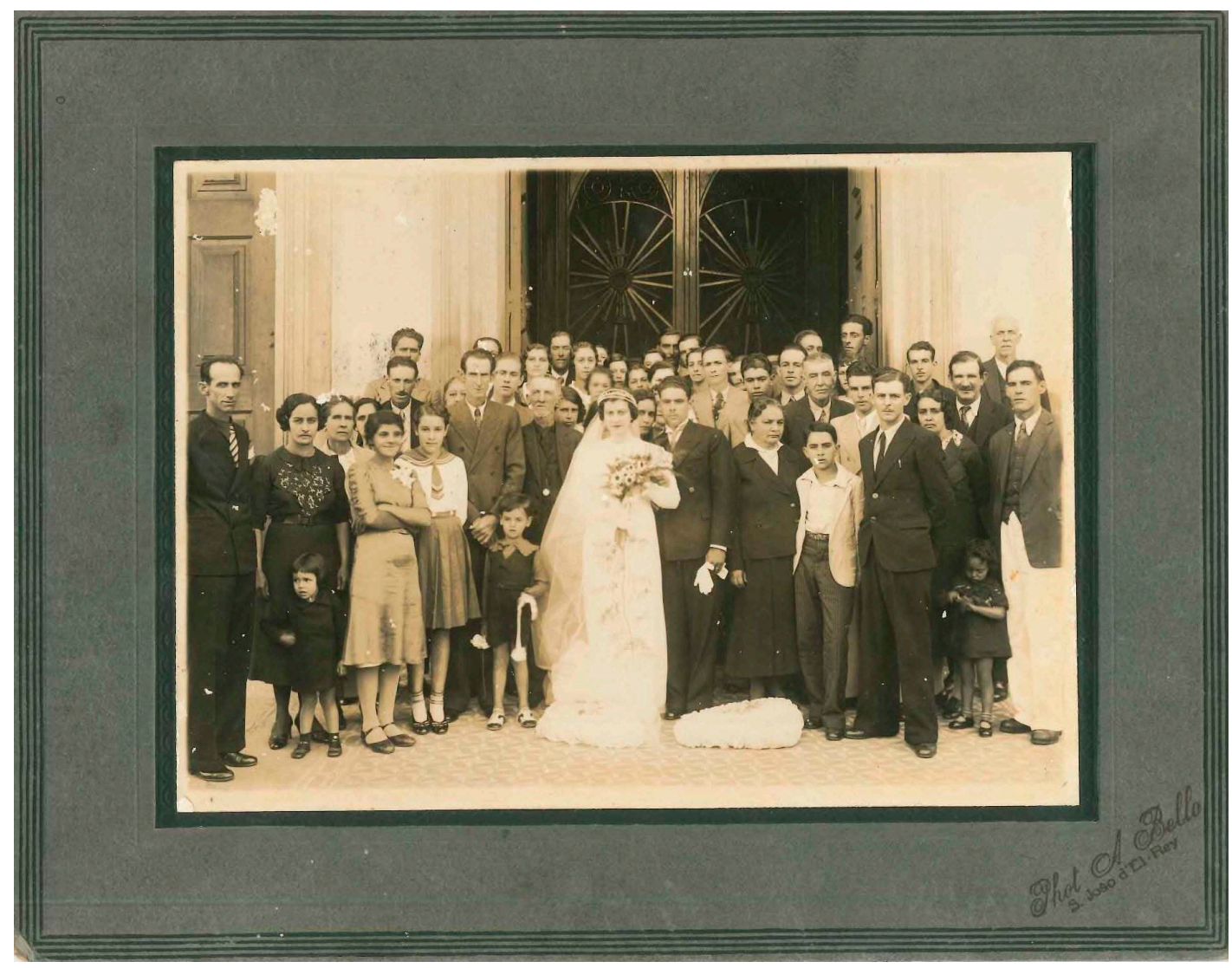

Foto 4. Casamento. Portal e escadaria da Igreja de São Francisco em São João del-Rey/MG. Década de 30). Fotografia de André Bello.

Interessam-me, assim, as relações que a fotografia possui com a memória, seja através do aspecto de fazer lembrar, seja no seu potencial performativo na história local, considerando-a, assim, como relevante testemunha sobre o olhar social associado às noções de traço e indício “que fica daquilo que não ficou" (Frehse 2005: 186). Nesse sentido, a fotografia, ao documentar presenças, interações, dimensões e arranjos sociais, acaba por apresentar também ausências e, dessa forma, chama-me atenção o seu potencial de representação no sentido maussiano de contiguidade no sentido da transferência de sentimentos através da materialidade (Mauss 2003: 101). 
Durante os percursos compreendidos na pesquisa, as conversas, tomaram como lugar privilegiado as casas de informantes. Esses espaços são aqui percebidos especialmente pelo protagonismo exercido pelas cozinhas que, através do pretexto da alimentação, se tornaram lugares para a recepção e para a prosa. Tomo como centralidade as proximidades e, as vezes, sobreposições entre o espaço íntimo e familiar, a memória e as fotografias que iam surgindo de acordo com os discursos e a hermenêutica nativa.

Nesse contexto de abordagens e relações, as fotografias surgiam de diversas formas. Em muitos momentos a sua vocação surgia como recurso narrativo - afirmativo ou negador - capaz de reforçar ou de intensificar algum fato ou ideia apresentada pelos informantes. Os retratos de família, as fotografias de eventos locais e a documentação de propriedades diversas revelavam-se no contexto das conversas como mecanismos para tornar visíveis e intensificadas as experiências orais relatadas.

"Eu vou ali buscar umas fotos para você entender"; "Vou te mostrar como era"; Eu tenho uma foto dele/dela para você conhecer". Ouvi frases como essas durante minhas experiências como pesquisador e a maioria delas tinha como função a "prova" no seu sentido de testemunha no tempo e no espaço de um fato ocorrido, de relações pessoais estabelecidas ou simplesmente

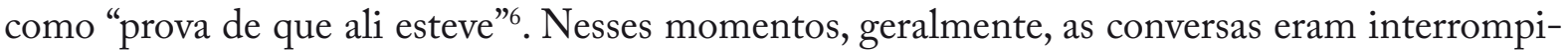
das para que o informante fosse até um outro cômodo no intuito de buscar fotografias, as quais poderiam ser apresentadas organizadas num álbum, dispersas em uma gaveta ou pasta ou em porta-retratos.

Nos álbuns, as fotografias eram geralmente apresentadas periodizadas por gerações e organizadas das mais antigas até as mais recentes. Como a grande maioria dessas fotografias não apresentava as respectivas informações de sua produção, não foi possível estabelecer as suas datas precisas, forçando os interlocutores a vasculhá-las no tempo através da rememoração de gerações e de eventos importantes como casamentos, batizados e festas religiosas. Essa forma de organização propiciava ao informante estabelecer linhas narrativas sequenciais - menos históricas do que estruturais ${ }^{7}-\mathrm{e}$, em alguns momentos, o próprio álbum se tornava o pretexto do assunto, invertendo, assim, o mote inicial daquela prosa. Para além de organizar e classificar experiências familiares, os álbuns pareciam oferecer a objetivação das temporalidades de uma família, uma espécie de resumo de trajetórias que, quando recontadas, ora se simplificavam, ora ganhavam novas possibilidades de interpretação constituindo-se, portanto, como um suporte identitário relevante para o (re)conhecimento do indivíduo num grupo.

De maneira geral, as fotografias encontradas surgiam dispersas sem que houvesse algum indício de organização por data e/ou tema. Nesse contexto, a maioria das fotografias foi apresentada sem a gravação de datas, ocasiões, lugares e pessoas, indiciando na relação com a ob-

6 Em sua etnografia realizada no norte de Goiás, Guedes (2013: 246) destaca a importância das fotografias nas realidades nativas como provas de que um indivíduo esteve em determinado local. Essas provas, assim como os "papéis”, da existência objetiva de fatos e de relações sócias .

7 Por outra perspectiva, posso aceitar que essa ordenação temporal obedeceria aquilo que Evans-Pritchard, ao analisar o modo de vida dos Nuer, chamou como temporalidade particular de classificação na qual a contagem - e a percepção - do tempo consistiria parcialmente na seleção de pontos de referência que sejam significativos no intuito de servir uma história comum, no caso, a história de uma família. Seguindo as inspirações causadas pelo antropólogo, a perspectiva temporal através da fotografia não se tornaria uma impressão verdadeira de "distâncias reais", mas sim um reflexo de relações entre linhagens. Dessa forma, tratamos não de verdadeiras posições na história, mas de posições na estrutura (2007: 121). Assim compreendo os álbuns de fotografia. 
servação de seus proprietários certo caráter de esquecimento. Tal constatação parte de momentos nos quais, quando indagados a respeito do arquivo, os informantes afirmavam que não conheciam "quase ninguém dali" ou que "era tudo gente morta já". No entanto, nem todas essas formas aparentemente "desorganizadas" dos arquivos fotográficos das famílias rurais que visitei eram desprovidas de classificações. Em algumas experiências, as próprias gavetas, pastas ou caixas onde eram guardadas as fotografias apareciam como mecanismo de demarcação da espécie dos arquivos, contrastando os desconhecidos dos familiares ou parentes, as mais velhas e as mais novas.

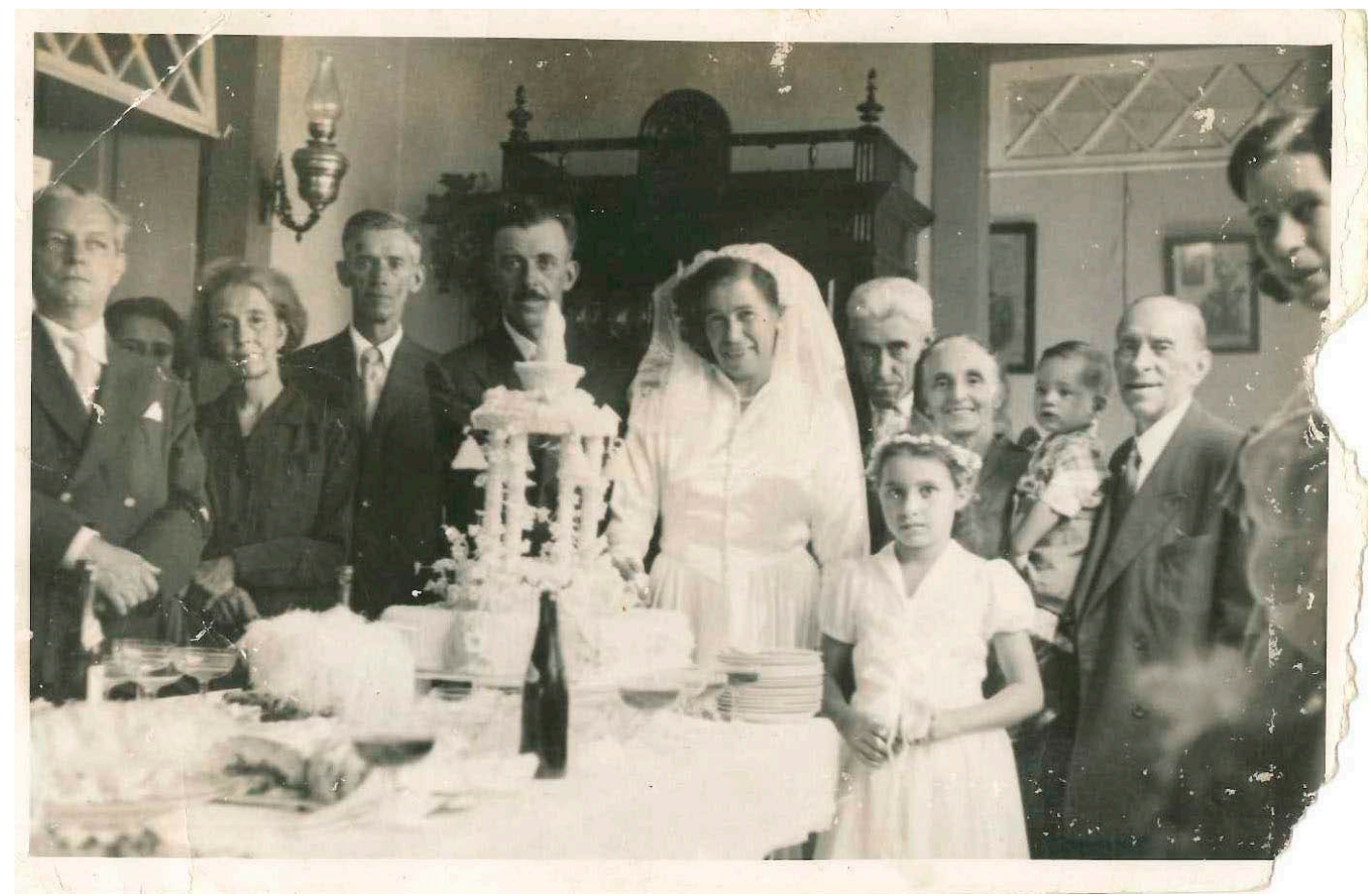

Foto 5. Casamento de um parente de Zeca do Carneiro. Data desconhecida.

Por fim, mas sem concluir, as fotografias também me foram apresentadas em porta-retratos. Geralmente encontrados em grande quantidade, ordenados sobre vastos móveis aparadores nas salas de visitas das moradas rurais, essa forma de organização das fotografias de família é geralmente apresentada a partir de sua relevância, destacando importantes eventos e marcos para aquela família. Por esse tipo, encontrei fotografias de casamentos nas quais a família é documentada ao redor dos noivos, em batizados e primeiras eucaristias, imagens de filhos e netos diante de algum feito de suas vidas (formaturas, premiações esportivas), entre outros. Essas fotografias podem ser consideradas como símbolo de sucesso social (Bourdieu; Bourdieu 2006: 34). Vale aqui destacar a importância dos eventos de cunho religioso na marcação do tempo familiar e na celebração e reiteração dos laços de parentesco.

\section{Leituras possíveis e a "Performance NA históRia"}

Nas três primeiras fotografias apresentadas a família assume centralidade temática no Rio das Mortes. Na primeira, trata-se de uma tipologia comum na fotografia do interior: a família, compreendida a partir de sua unidade, retratada em frente à sua morada. Esse tipo de ima- 
gem era comum nos retratos produzidos por fotógrafos itinerantes, os quais eram comumente idealizados para compor os álbuns de fotografia da família. A composição clássica indicia sociabilidades do passado nos elementos que lhe são comuns como, por exemplo, a centralidade e protagonismo dos pais e o ordenamento etário (os filhos e filhas mais novos encontram-se assentados à dianteira, e os mais velhos, de pé, no plano mais profundo da imagem).

Essas disposições na imagem compreendidas por poses e semblantes denotam gêneros, dialetos de estilo, intensões, usos do espaço e de relações e estratégias retóricas repletas de expectativa. Arrisco dizer que essas fotografias carregam o intuito de dizer a família como modelo e paradigma de relações morais e hierárquicas num contexto da classe dominante. Nesse sentido, a fotografia apresenta uma qualidade performativa, tanto literal quanto metaforicamente (Edwards 2002: 16).

No gênero representado pela primeira fotografia destaco a pose como centralidade na construção da imagem que se espera. O tempo de exposição para que o retrato fosse feito obrigava àqueles que estavam sendo fotografados a permanecerem imóveis durante muito tempo fazendo com que o dever de imobilidade contagiasse também os semblantes e expressões. Dessa forma, é comum perceber nesses retratos a postura rebuçada e firme, também respaldadas pela seriedade pelo qual o evento era encarado pelos mais velhos. É por isso que, segundo Vasquez, nos retratos antigos não há sorrisos e até as crianças permanecem com semblantes firmes, atuando como "espelhos" dos desejos paternos (1983: 30-31)

Nesses processos realizados por retratistas itinerantes, o ato de fotografar costumava mobilizar as famílias durante todo um dia de preparativos no qual se escolhia a melhor roupa e o melhor cenário para serem devidamente gravados e eternizados como expressão de costumes individuais e familiares. Como um verdadeiro evento, o retrato de família compreendia uma relação específica com o tempo no qual se suspendiam as atividades cotidianas da casa e do campo em função de um "dever de memória" 8.

Na segunda imagem, a documentação de um casal de "desconhecidos" também representa um tipo comum nas fotografias do final do século XIX e início do XX. Trata-se de uma carte de visite representativa da união de um casal. Nessa imagem, a esposa, em pé, aparece com uma das mãos "levemente" repousada sobre os ombros do marido assentado ${ }^{9}$. Como um arranjo comum submetido a certo tempo de exposição frente ao retratista, destaco a indumentária nobre - indício da luxuosidade do tipo fotográfico em questão - e postura esguia e firme diante da expectativa da imagem. Imagens como essa, são geralmente compostas a partir das sugestões ou ordens dos retratistas (SCHWARCS, 2003) cuja repetição de arranjos pôde criar padrões e taxionomias.

A imagem traz, nos termos de Freyre, a "fisionomia de uma união" (1983: 18) contida no seu potencial de leitura das estruturas patriarcais no Brasil. Tal registro dispõe tipos físicos, trajos e adornos característicos de uma época específica, os quais são itens que testemunham socia-

$8 \mathrm{Em}$ diversos momentos da pesquisa pude ouvir o quão importantes eram esses dias nos quais os retratistas visitavam as famílias. Paravam-se todas as atividades, as crianças permaneciam em casa na expectativa da chegada do retratista e todo um processo cerimonial era construído no intuito de que o retrato traduzisse toda uma ideia comum do pertencimento à família nas suas qualidades morais e estéticas.

9 Rapara-se que a outra mão da mulher encontra-se rija e firme acompanhando a silhueta do vestido, fato que reitera o caráter rígido do momento de exposição. 
bilidades instruídas pela autoridade do homem-marido e a assistência constante da mulher-mãe no sentido da valorização da ancestralidade dos troncos. ${ }^{10}$

Outro importante e constante traço desse tipo fotográfico é a presença da religiosidade a partir de iconografias típicas dos atos de devoção. Normalmente encontrei imagens nas quais as mulheres seguravam um terço.

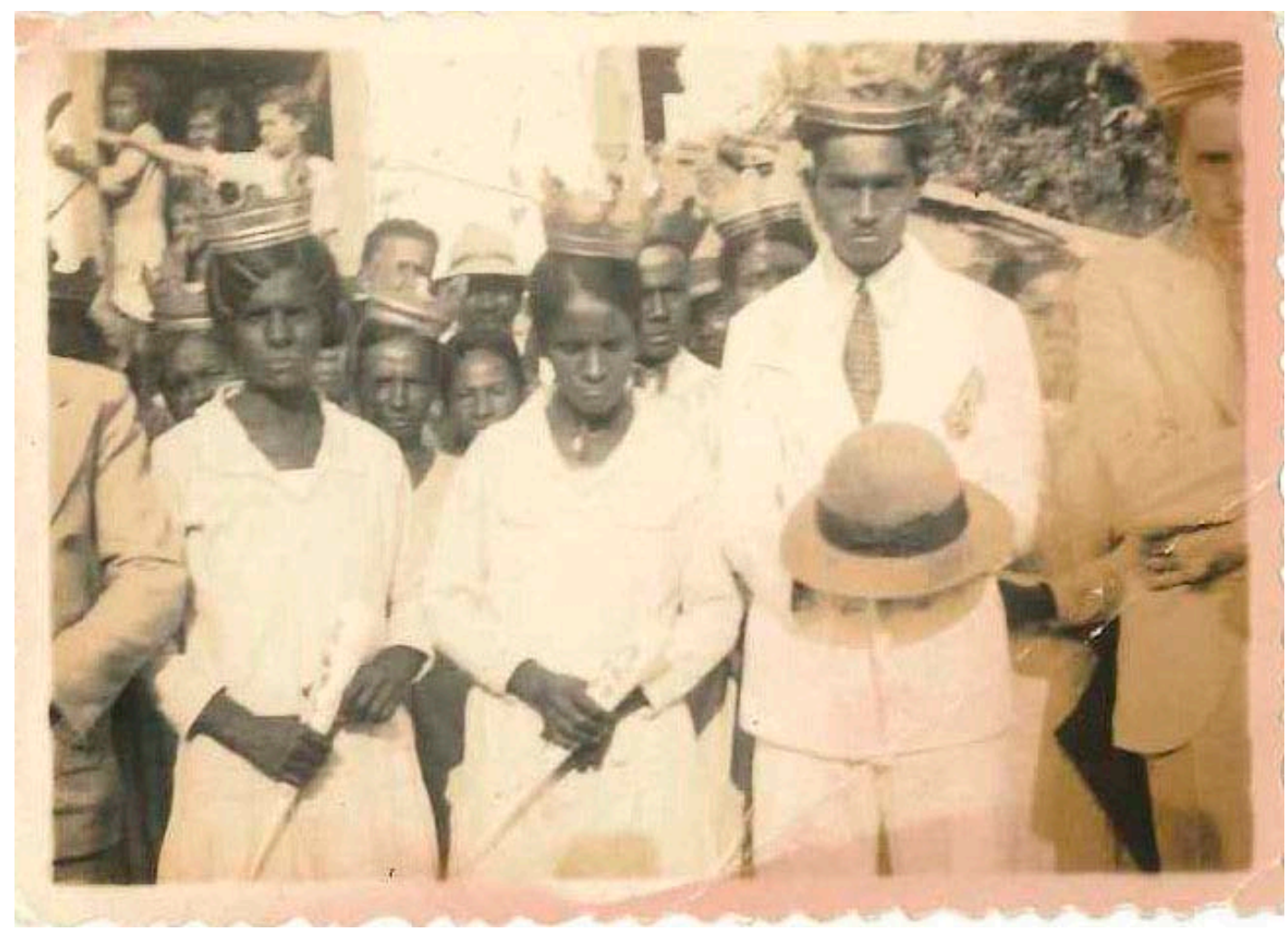

Foto 6. Festa de Reinado. Data desconhecida.

Sem se distanciar muito do caráter performativo das primeiras duas imagens, a terceira evidencia, de uma maneira mais intensa, a encenação ou a teatralidade no retrato. Esta parte de arranjos narrativos claros na intensificação de posturas femininas e românticas nas suas modas e cabelos da época, no cruzar delicado das pernas à altura dos tornozelos. Sem, no entanto, tratar especificamente do gênero teatral, a leitura antropológica desse retrato de irmãs destaca o nexo existente entre a intensidade performática das retratadas e o momento histórico no qual a fotografia se inscreve, sugerindo, então, a sua qualidade como "experiência do passado" (Edwards 2000: 22). Dessa forma, como potencial de recordações de um tempo, as fotografias podem oferecer verdadeiros "quadros mentais" no sentido de Halbwachs, ou seja, podem se tornar ou significar eventos pontuais que marcam o sentido de tempo na sua conversão em época, e - no

10 Para Comerford (2003: 3), assim como os termos parentes, parentesco, família, gente e raça, os troncos são usados na região da Zona da Mata mineira para definir um campo de relações de confiança, ajuda mútua, tolerância, intimidade, bem como para definir diferentes graus de compartilhamento de características e responsabilidades. Os troncos são, assim, uma expressão de referência aos ascendentes de uma família no seu sentido de origem e na conexão com a tradição. No sentido dessa abordagem, estendo essa noção à ideia de tempo parental na qual os troncos designam uma forma de o indivíduo se localizar no tempo e no espaço. Assim, não se restringindo apenas à filiação no seu sentido estrito, a categoria tronco indicia a ancestralidade da família antiga no seu potencial de identificação no presente dos referenciais de transmissão de relações e moralidades (Franco 2013) 
caso dessa imagem - em moda, de modo a recuperar o sentido do “acontecimento" (1990: 101).

Outro importante aspecto desse retrato é a existência de um cenário típico dos estúdios fotográficos ou "salões de poses" localizados nas cidades. Como já mencionado na introdução deste ensaio, esse tipo de imagem traz padronizações de poses e composições do espaço. No retrato, identifica-se a existência de um cenário de fundo: uma pintura na parede contendo cortinas e colunas, elementos típicos da arquitetura luxuosa dos sobrados urbanos.

Argumento, diante dessas reflexões, que as fotografias podem ser compreendidas pela sua materialidade (Edwards 2009: 131). Dessa forma, como itens de composição de álbuns, cartes de visites ou porta-retratos, a imagem física é composta por expectativas culturais e visões de mundo que, por sua vez, se tornam construções padrões voltadas para a venda (Schwarcs 2003).

Misturam-se, dessa forma, cosmologias no intuito de demonstrar modelos, expectativas e aspirações de sociabilidade. No entanto, não se deve esquecer que mesmo interpretada no seu grau de performatividade no tempo e no espaço, a fotografia inscreve-se como projeto de memória.

Como tal, a fotografia compõe (pseudo)presenças e ausências na imagem como relatos de um sentido de grupo e de relevância em eventos e em relações sociais (parentais). Possuir essas recordações, nesse sentido, é uma forma de preservar relações sociais na tentativa de reconciliação no tempo de alianças, afetividades e prestígios. Abaixo, surgem algumas fotografias sobre contextos festivos, nos quais, pelo pretexto do espaço de sociabilidade da fé e da família, indiciam o caráter cerimonial do ato de fotografar e de ser fotografado (eternizado, gravado...).

As cinco últimas imagens contrastam com as três primeiras em alguns aspectos constitutivos que dialogariam com a própria história da fotografia no interior de Minas Gerais. Enquanto as primeiras apresentam posturais mais rígidas a partir de planos temáticos mais definidos (cenários e poses), as segundas deixam intuir certa flexibilidade em tais arranjos. Entendo por essa interpretação o fato de que o segundo grupo de imagens apresenta posturas mais despojadas em dimensões cotidianas mais intimistas e, portanto, mais distantes daqueles contextos mais formais contidos nos chamados dia da fotografia, quadro que, como sugerido, confinava a produção da imagem a contextos estéticos mais normativos. Isso pode ser explicado pelo fato de que, de um grupo ao outro, a presença de fotógrafos ou retratistas ambulantes se torna mais intensa e repetitiva, podendo estes documentar festas familiares e religiosas e até o cotidiano das comunidades rurais.

No entanto, esse processo de popularização da fotografia e do fotógrafo não faz desaparecer a qualidade cerimonial contida em tais imagens e, menos ainda, tornaria menos intensa as substâncias performativas nas posturas, arranjos e evidências. As imagens, então, parecem manter a sua tendência ao "extra-ordinário", ou seja, àqueles momentos afastados da rotina quotidiana os quais estariam insertos nos ritmos e rituais familiares geralmente associados ao lazer e à passagem do tempo (Caetano 2007: 73-74)

Assim como as primeiras, as imagens desse segundo grupo traduzem, num certo sentido, indícios dos sentidos de grupos vivenciados na história e na memória local do Rio das Mortes ao passo em que trazem elementos organizados para um determinado fim o qual seria o de evidenciar as principais qualidades dos acontecimentos vividos, justificando-os mais por aquilo 
que representam e menos pela sua representação em si (Caetano 2007: 74).

A existência dessas imagens não permite, naturalmente, que acedamos efetivamente ao cotidiano local da época e, portanto, aos modos mais rotineiros de relações dessas pessoas com os espaços e tempos. No entanto, as interpretações realizadas pelos informantes acerca das festas e cerimônias retratadas são capazes de trazer a tona, mesmo que de forma selecionada tanto nos elementos da imagem quanto nas leituras "nativas", traços e vínculos pessoais ao mesmo tempo em que posiciona os indivíduos, no passado e no presente, diante dos costumes, práticas e crenças do local.

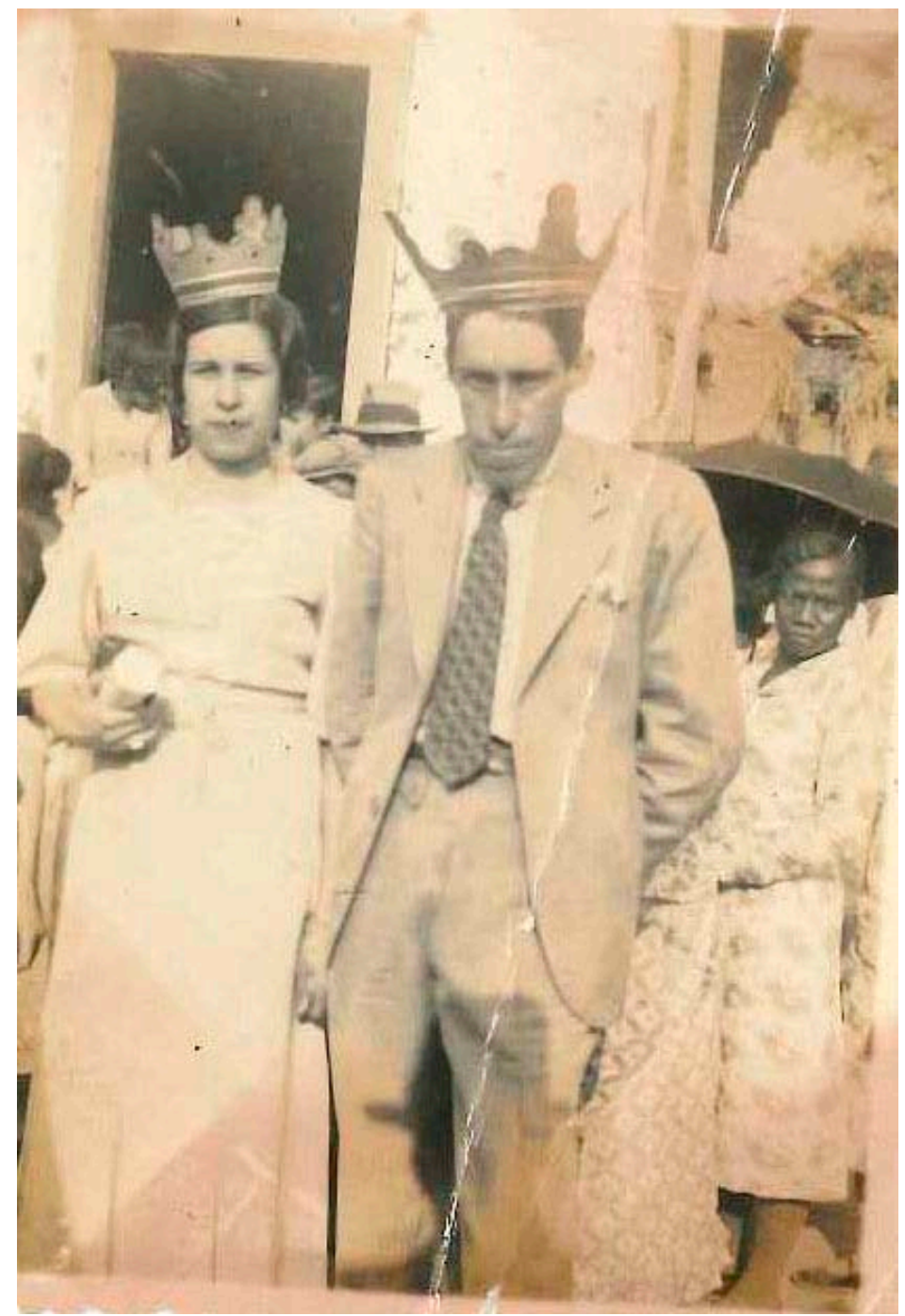

Foto 7. Zeca do Carneiro e esposa na festa de Reinado (Nossa Senhora do Rosário), 25/08/1935.

As fotografias de casamentos, quando "descongeladas" em contemplações e interpretações realizadas pelos informantes no campo, revelam o seu potencial de mapeamento de presencias e ausências. Nesse sentido, como sugere Bourdieu, na leitura de fotografias desse tipo pode-se averiguar quem participou ou não da cerimônia, a constituição dos casais e as configurações de alianças pessoais. Nesse sentido, a ausência poderia indicar discórdias ou dissidências e as 
presenças atestariam a honra (2006, p 34) ou a solidariedade entre os grupos de parentesco ${ }^{11}$.

Essas fotografias, dispostas em álbuns ou em porta-retratos constituem-se como testemunhas da importância e pompa da cerimônia, marcando, por exemplo, a quantidade de convidados e o tamanho da família ou parentela como traço constituinte do prestígio local. Portanto, a fotografia possui importante papel na demarcação das famílias mais importantes na comunidade e, por consequência, concede distinção a indivíduos nela inscritos.

Pelo outro lado da imagem produzida, a presença do fotógrafo também confere relevância e prestígio aos eventos. Nesse sentido, tanto o ato de fotografar, quanto as narrativas propiciadas pela fotografia, concedem uma cerimonialidade específica aos momentos vividos. Esse aspecto pode ser percebido nas fotografias de festas religiosas e populares, nas quais os indivíduos em indumentárias específicas do rito posam de maneira cerimonial para o fotográfico como que se o ato de fotografar provocasse a intensificação ou teatralização das posturas e percepções da festa. Diante da expectativa da imagem, portanto, procura-se sintetizar narrativamente as experiências de devoção e de representação cultural, de modo a tornar mais visíveis as principais iconografias e os mais centrais sentidos da festa retratada.

\section{Considerações finais}

Empreender análises sobre percepções sociais do tempo e do espaço histórico na vida cotidiana implica, de acordo com Frehse, em certa abdicação de quaisquer pretensões historicistas. Dessa forma, tendo em mãos documentos iconográficos, o pesquisador acaba por possuir construções a respeito de tempos passados e nunca do próprio passado. Isso implica em interpretações pautadas por fragmentos presentes na imagem os quais se constituem como pequenos detalhes que, apesar de aparentemente insignificantes para quem vê, possuem um grande potencial heurístico (2005: 29). É, então, a partir da relação entre esses detalhes que surgem indícios de contextos socioculturais relevantes os quais, intensificados na imagem, revelam comportamentos e formas de perceber o mundo no qual se está inserto.

Se as fotografias de famílias indiciam formas de ver, imitar, representar, compor e projetar o mundo, posso confiar na sua potencialidade enquanto reveladoras de informantes na pesquisa etnográfica. Nesse sentido, ao mesmo tempo em que a fotografia pode documentar hábitos, posturas e arranjos sociais variados, ela pode se constituir como mecanismo social de intervenção na produção e na manutenção de relações sociais no momento em que se torna um corpus destinado à memória no seu sentido de servir a um senso de realidades presentes. Os arquivos fotográficos deixam, portanto, o lugar de fetiche nostálgico ou de ilustração na pesquisa, para assumir dimensões dinâmicas nas quais a transformação possui centralidade analítica.

Por fim, tais reflexões nos permitem relacionar este ensaio aos empreendimentos conceituais estimulados por Latour (2005), os quais são designados a partir de propostas e movimentos de "simetria". Diante dessa possibilidade de "modelo etnográfico", valorizam-se de forma

11 Poderíamos pensar essa questão também em diálogo com os estudos de Campbell (1964: 114) sobre os pastores gregos. Nesse contexto nativo, as festas, para além de uma consideração utilitarista da associação interessada, integram parentes distantes no sentido afetivo. Assim, a presença de um convidado no casamento indicaria efetiva solidariedade entre a sua família e a família do noivo ou da noiva e a ausência, o contrário. 
contínua e crescente figuras, materiais ou imateriais, que venham compor nossas etnografias de modo que a autoria - modo privilegiado de se conceber a etnografia - tenha os limites borrados no âmbito da definição de alteridade (Borges, 2010: 12). Assim, congregam-se sujeitos e objetos, retirando dos primeiros a centralidade privilegiada de diálogo antropológico, e, fazendo emergir na interlocução os chamados "silêncios", "não-ditos", enfim, os elementos significativos na ordem dos variados discursos, proporcionando-os a repensar os sentidos da memória e da história a partir de seus possíveis diálogos com a antropologia. Trata-se, portanto, de não trabalhar apenas a partir de imagens, mas com elas.

\section{Biblografia}

Arruda, Rogério Pereira de. 2013. O ofício da fotografia em Minas Gerais no século XIX $1845-$ 1900. Belo Horizonte: Edição do autor.

Barthes. Roland. 1977. "Rhetoric of the Image". In Image - Music-Text. Sel. and Trans. Stephen Heath. New York: Hill and Wang, 1977, pp. 32-51.

Borges, Antonádia. 2010. "Uma propriedade, diversas propriedades: etnografia, comparação e a distribuição de benefícios públicos no Brasil e na África do Sul”. In: NEIBURG, Federico; SIGAUD, Lygia [et al.]. Brasil em Perspectiva, Rio de Janeiro: 7 Letras.

Bourdieu, Pierre \& Bourdieu, Marie-Claire. 2006. "O camponês e a fotografia". Revista de Sociologia Politica, Curitiba, 26, p. 31-39.

Burke, Peter. 2001. Eyerwitnessing. The Uses of Images as Historical Evidence. Ithaca, Cornell University Press.

Caetano, Ana. 2007. "Práticas fotográficas, experiências identitárias. A fotografia privada nos processos de (re)construção das identidades”. In Sociologia, problemas e práticas, nº 55, 2007. pp. 69-89.

Campbell, J.K. 1964. Honour, Family and Patronage. A study of institutions and moral values in a greek mountain community. Oxford: Oxford press.

Comerford, John C. 2003. Como uma família: sociabilidade, territórios de parentesco e sindicalismo rural. Rio de Janeiro: Relume-Dumará: Núcleo de Antropologia da Política/ UFRJ.

Franco, Maria Sylvia de Carvalho. 1997. Homens livres na ordem escravocrata. 4. Ed. São Paulo: Fundação Editora UNESP.

Franco, Paulo Augusto. 2013. A casa e o "tronco". A família e o Juiz de Paz no Rio das Mortes. Artigo apresentação na XIV Jornada do PPGSA.

Edwards, Elizabeth. 2002. "Photography and Performance of History". Kronos. Journal of Cape History, 42.

2009. "Photography and the material performance of the past". History and Theory. Theme Issue 48 (December), 130-150.

Evans-Pritchard, E, E. 2007. "Tempo e Espaço", em Os Nuer: uma descrição do modo de subsistência e das instituiçóes politicas de um povo nilota. São Paulo: Perspectiva, pp. 107-150.

Frehse, Fraya. 2005. O Tempo das Ruas na São Paulo de Fins do Império. São Paulo: Editora da Universidade de São Paulo.

Freyre, Gilberto. 1983. "Por uma sociofotografia”. In FREYRE, Gilberto; PONCE DE LEON, Fernando; Vasquez, Pedro. O retrato brasileiro: fotografias da Coleção Francisco Rodrigues, 1840-1920, Rio de Janeiro: Funarte/Núcleo da Fotografia, Fundação Joaquim Nabuco/ Departamento de iconografia, p. 15-26. 
Guedes, André Dumans. 2013. O trecho, as mães e os papéis. Etnografia de movimentos e durações no norte de Goiás. São Paulo: Garamond.

Halbwachs, Maurice. 1990. A memória coletiva. Rio de Janeiro: Vértice.

Kossoy, Boris. 2002. Dicionário historico-fotográfico brasileiro: fotógrafos e o ofício da fotografia no Brasil (1831-1910). São Paulo: Instituto Moreira Sales.

Latour, B. Reassembling the Social. An Introduction to Actor-Network-Theory. Oxford: Oxford University Press, 2005.

Lévi-Strauss, Claude. 1965. Le totémisme aujourd'hui. Deuxième édition. Paris: Presses Universitaires de France.

Martins, José de Souza. 2002. "A imagem incomum: a fotografia dos atos de fé no Brasil". Estudos Avançados 16 (45). São Paulo.

Mauss, Marcel. 2003. "Esboço de uma teoria geral da magia”, In Sociologia e antropologia. Tradução: Paulo Neves. São Paulo: Cosac Naify.

Novaes, Sylvia Caiuby. 1998. "O uso da imagem na Antropologia”. In Samain, Etienne (org.). O fotográfico. São Paulo: Hucitec: CNPq.

Parente, José Inácio. 1987. Rio de Memórias. Obra de cinema documentário.

Schwarcz, Lilia Moritz. 2010. Imagens da Escravidão. Fotografias do IMS, 2003 Disponível em: http://ims.uol.com.br/imagensdaescravidao/

"Entrevista com Lilia Moritz Shwarcz", em Oficina do Historiador, Porto Alegre, EDIPUCRS, v.1, n.1.

Vasquez, Pedro. 1983. “Olha o 'passarinho'! Uma pequena história do retrato”. In FREYRE, Gilberto; PONCE DE LEON, Fernando; VASQUEZ, Pedro. O retrato brasileiro: fotografias da Coleção Francisco Rodrigues, 1840-1920, Rio de Janeiro: Funarte/Núcleo da Fotografia, Fundação Joaquim Nabuco/Departamento de iconografia, p. 27-34.

\section{BETWEen the VISIBLE AND THE INVISIBLE: THE ETHNOGRAPHIC POTENTIAL OF FAMILY portraits in a RURAL COMmunity In Minas Gerais, Brazil}

Based on images collected during two years of ethnographic research in Santo António do Rio das Mortes Pequeno in the rural district of São João del Rei, Minas Gerais, Brazil, this paper explores the anthropological potential of family portraits. It is suggested that the photographs - hovering between the visible and the invisible and generating indices of cultural signification from a certain époque represent, at the same time, visions and an interpretations of social realities. If visions are choices and therefore the results of social processes, then photographs belong to social places of production, subject to a number of formal, aesthetical and moral patterns dominant during a certain period in history. Taking into account the many aspects of and the numerous roles played by photographs and photographers in Minas Gerais' rural area, the author suggests the use of portraits in ethnographic practice, highlighting. its potentials for suggesting/revealing the gaze which had produced it. A collection of family images is presented, pointing to notions of performativity and representation of memories.

Keywords: photography, ethnography, family, memory, rural spaces 